\title{
MENDEFINISIKAN ENTERPRISE ARCHITECTURE PLANNING DALAM PERENCANAAN INTEGRASI SISTEM INFORMASI PERPUSTAKAN SEKOLAH
}

\author{
Agung Baitul Hikmah \\ AMIK BSI Purwokerto \\ Jalan Dr. Bunyamin No.106, Pabuaran Purwokerto \\ agung.abl@bsi.ac.id
}

\begin{abstract}
A school library is a place which serves many things for student and academic civitas needing. The Existence of school library is something important in the school environment to fulfill all of needs and interests which can be got from the the library, so the concept of library needs a new concept which can give more benefits from its existence. The concept of enterprise Architecture Planning is able to arrange a layout to realize a new concept for existencing a library, such as The information system integration for a library. In this Research.the researcher makes enterprise architecture to integrate the information system of school library such as : in SMUN 1 Tasikmalaya, SMU SIliwangi Tasikmalaya,SMK MJPS Tasikmalaya, SMK Bina Lestari PUI Tasikmalaya. Based on the business process which is run by every library, EAP can show a blueprint for the architecture of integration library information system which involves business architecture, application architecture, information architecture and technology architecture.
\end{abstract}

Keyword: Enterprise, Arsitektur Enterprise, Integration Library Information System, SIPT.

\begin{abstract}
Abstrak - Perpustakaan sekolah adalah tempat yang menyajikan banyak hal untuk mahasiswa dan membutuhkan civitas akademik. Keberadaan perpustakaan sekolah adalah sesuatu yang penting dalam lingkungan sekolah memenuhi semua kebutuhan dan kepentingan yang dapat dapatkan dari Perpustakaan, sehingga konsep Perpustakaan kebutuhan sebuah konsep baru yang dapat memberikan manfaat lebih dari keberadaannya. Konsep arsitektur perencanaan perusahaan ini mampu mengatur sebuah layout untuk mewujudkan sebuah konsep baru untuk existencing sebuah perpustakaan, seperti informasi sistem integrasi untuk Perpustakaan. Dalam penelitian ini, peneliti membuat arsitektur perusahaan untuk mengintegrasikan sistem informasi perpustakaan sekolah seperti: di SMUN 1 Tasikmalaya SMU Siliwangi Tasikmalaya, SMK MJPS Tasikmalaya, SMK Bina Lestari PUI Tasikmalaya. Berdasarkan proses bisnis yang dijalankan oleh setiap Perpustakaan, EAP dapat menunjukkan cetak biru untuk arsitektur integrasi sistem informasi perpustakaan yang melibatkan arsitektur bisnis, arsitektur aplikasi, arsitektur informasi dan teknologi arsitektur
\end{abstract}

Kata Kunci: Perusahaan, Perusahaan Arsitektur, Integrasi Sistem Informasi Perpustakaan, SIPT.

\section{PENDAHULUAN}

Menurut Undang-Undang RI No 43 Tahun 2007 Pasal Ayat 1 bahwa Pengertian perpustakaan secara umum "Perpustakaan adalah pengelola koleksi karya tulis,karya cetak, dan/atau karya rekam secara professional dengan sistem baku guna memenuhi kebutuhan, penelitian, pelestarian, informasi dan rekreasi para pemustaka".

Perpustakaan sekolah merupakan bagian integral dari program sekolah secara keseluruhan, dimana bersama-sama dengan komponen pendidikan lainnya turut menentukan keberhasilan proses pendidikan dan pengajaran. Melalui perpustakaan siswa dapat mendidik dirinya secara berkesinambungan (Darmono, 2007).

Perpustakaan dituntut untuk dapat memberikan sebuah layanan informasi pada pengguna yang tepat dengan waktu yang cepat. Layanan dapat terlaksana dengan baik apabila perpustakaan dapat menghadirkan dan memanfaatkan perkembangan teknologi informasi dalam pengelolaan perpustakaan (Ishak, 2008).

Kondisi diatas terjadi pula pada organisasi lain, terutama organisasi pendidikan. Pada institusi pendidikan terlihat jelas setiap institusi membangun dan mengembangkan sistem 
informasinya sendiri-sendiri, termasuk pada sistem informasi yang dibangun untuk perpustakaan mereka. Pada umumnya sistem informasi perpustakaan dibangun untuk membantu proses bisnis dilingkungan masingmasing. Kendala tersebut terjadi pula pada SMU dan SMK di Tasikmalaya yaitu pada SMUN1 Tasikmalaya, SMU Siliwangi, SMK MJPS2 Tasikmalaya, SMK Bina Lestari PUI Tasikmalaya. setiap perpustakaan di sekolah tersebut masih mengalamai kendala dalam pelayanan kepada siswa terutama dalam hal terbatasnya koleksi data buku yang dimiliki oleh perpustakaan sekolah masing-masing sehingga proses pencarian dan peminjaman buku ke sekolah lain mengalami kesulitan karena tidak semua sekolah memiliki koleksi data buku yang memadai akibat belum terintegrasi satu sama lain.

Berdasarkan latar belakang diatas, permasalahan utama yang akan dikaji adalah Bagaimana mendefinisikan enterprise architecture planning (EAP) untuk pemodelan arsitektur enterprise integrasi sistem informasi perpustakaan sekolah Kota Tasikmalaya serta Bagaimana model standar arsitektur enterprise yang sesuai untuk diterapkan di Kota Tasikmalaya. Sehingga dapat memperlihatkan seluruh kebutuhan akan implementasi integrasi sistem informasi perpustakaan sekolah di Kota Tasikmalaya

\section{KAJIAN LITERATUR}

\section{Enterprise Architecture}

Enterprise Architecture adalah deskripsi spesifik dan dokumentasi hubungan saat ini dan yang diinginkan antara operasi dan proses manajemen dan teknologi informasi (Fri, 2007). Dengan bantuan Enterprise Architecture, sebuah perusahaan atau organisasi dapat mengatasi dinamika bisnis dengan mencoba untuk mengintegrasikan, mengatur dan menganalisa elemens sistem (Rajabi, et al, 2013). Dimana Karakteristik utama sebuah Enterprise Architecture adalah kemampuan dalam menyediakan cara pandang yang menyeluruh tentang sebuah Enterprise. Suatu Enterprise Architecture yang baik diharapkan dapat menyeimbangkan kebutuhan organisasi dan memfasilitasi adanya translasi strategi kedalam operasi sehari-hari.

\section{Kerangka Zachman}

Pada dasarnya kerangka kerja Zachman untuk Enterprise Architecture adalah sebuah skema yang digunakan untuk mengelola artifak suatu enterprise. Kerangka Kerja Zachman terdiri dari enam baris dan enam kolom (Fatolahi and Shams, 2006) Kerangka kerja Zachman idesain untuk memasukkan representasi arsitektur sistem informasi untuk semua pihak yang terlibat dalam kegiatan pengembangan, pengelolaan, perawatan, dan penggunaan dari sistem informasi suatu organisasi.

Elemen kerangka kerja Zachman ditunjukkan sebagai sel-sel seperti terlihat pada Gambar dibawah ini:

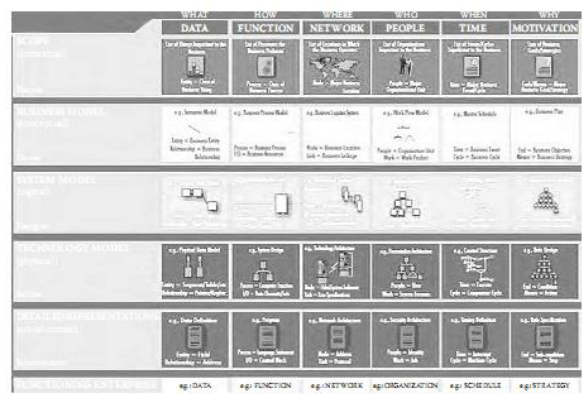

Gambar 1

Pendekatan EA dalam Kerangka Zachman

\section{Enterprise Architecture Planning (EAP)}

Enterprise Architecture Planning (EAP) merupakan metode yang dikembangkan untuk membangun arsitektur enterprise. (Surendro, 2007).

Enterprise Architecture Planning merupakan kegiatan merencanakan, sehingga aktifitas yang dicakupnya yang terkait kerangka kerja Zachman adalah mendefinisikan data, aplikasi dan teknologi dari dua persfektif pertama, yaitu persfektif perencana (planner) persfektif pemilik (owner)

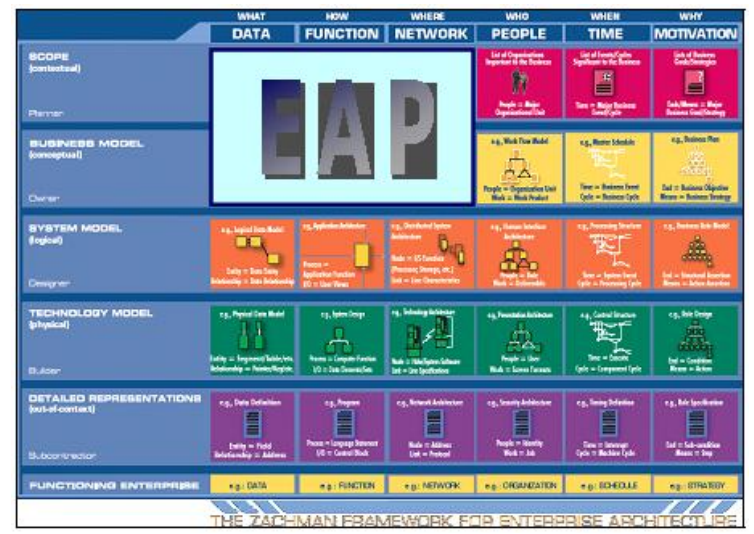

Gambar 2

Pendekatan EAP dalam kerangka zachman Sumber: Surendro (2007)

Dari aspek cakupannya berdasarkan klasifikasi kerangka kerja Zachman, EAP 
melibatkan 7 sel, yang masing-masing dibangun melalui 4 tahap

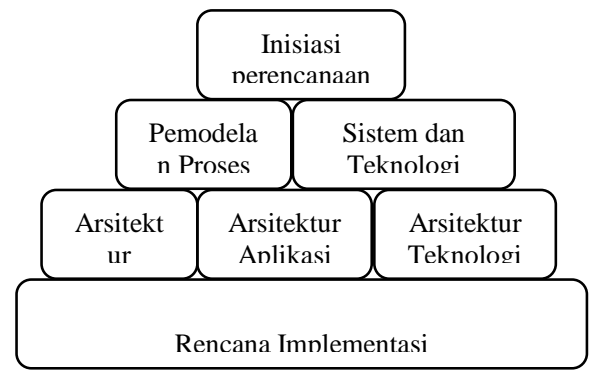

Tahapan

Tahapan

Tahapan

Tahapan

Gambar 3 Tahap Perencanaan EAP Sumber: Surendro (2007)

\section{METODE PENELITIAN}

Pada penelitian ini langkah-langkah penelitian mengacu pada metodologi Enterprise Architecture Planning (EAP). Sedangkan bahan penelitian yang dibutuhkan peneliti terdiri dari data primer dan data sekunder Data primer didapat dengan melakukan wawancara terhadap pihak terkait dengan penelitian sedangkan data sekunder didapat dengan pengumpulan dokumentasi atau laporan dari sumber data.

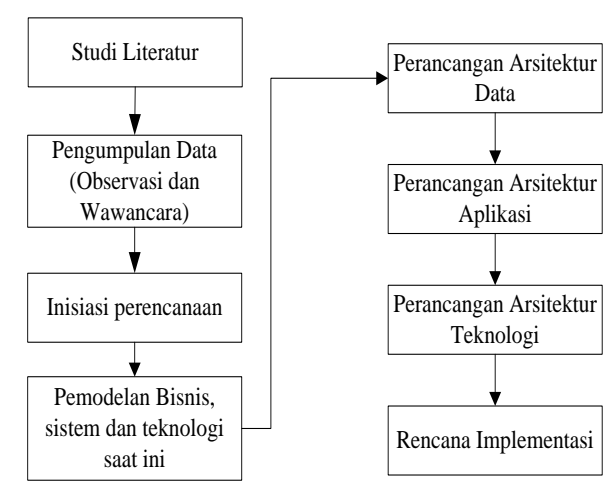

Gambar 4

Tahapan Metode Penelitian

Sumber: Minoli (2008)

\section{PEMBAHASAN}

\section{Analisa Enterprise Architecture Planninig}

\section{Inisiasi Perencanaan}

a. Menentukan ruang lingkup dan sasaran perencanaan arsitektur enterprise.

b. Menentukan Tujuan

c. Menentukan Metodologi
2. Pemodelan Bisnis dan Teknologi saat ini

a. Mendefinisikan area-area fungsional utama menggunakan konsep "value added" Michael Porter.

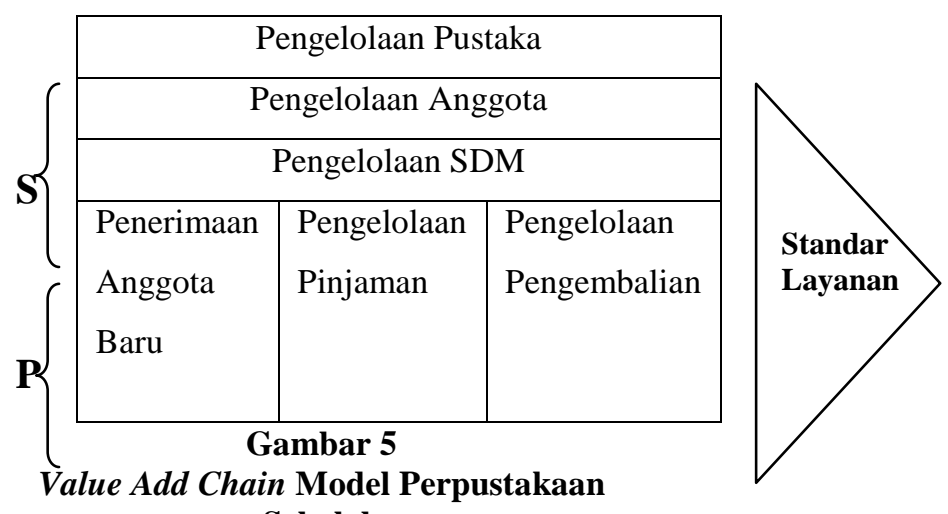

b. Memecahkan tiap area fungsional menjadi sub fungsi menggunakan Four Stage Life Cycle Bussiness System Planning.

c. Sistem dan Platform Teknologi Saat Ini

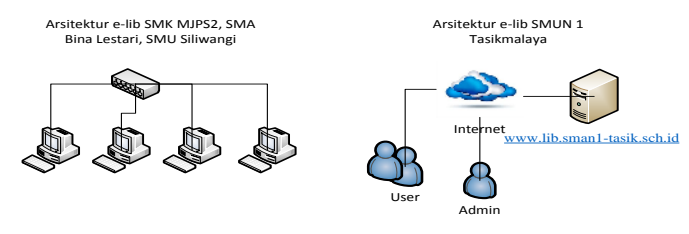

d. Analisa Kondisi Entrprise saat ini

Tabel 1

Matrix Internal Factors Analysis Summary (IFAS)

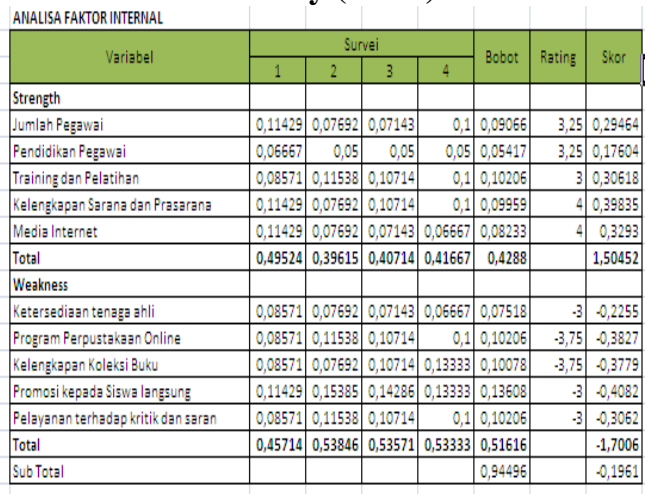

Tabel 2 


\section{Matrix External Factors Analysis Summary (EFAS)}

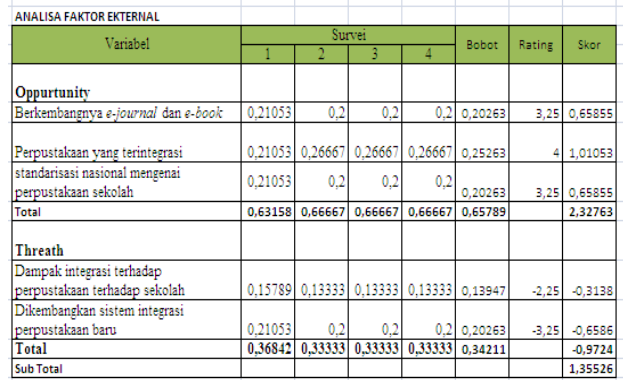

Hasil analisis table 1 menunjukkan bahwa faktor-faktor kekuatan nilai total skornya 1,504522 sementara nilai total skor faktorfaktor kelemahannya -1,70062. Selanjutnya nilai total skor dari faktor-faktor kekuatan dikurangi nilai total skor faktor-faktor kelemahannya, maka hasilnya adalah selisih Negatif sebesar -0,1961. Sedangkan Hasil analisis table 2 menunjukkan bahwa faktorfaktor peluang nilai total skornya 2,327632 sementara nilai total skor faktor-faktor ancamannya $-0,97237$. Selanjutnya nilai total skor dari faktor- faktor peluang dikurangi nilai total skor faktor-faktor ancamannya, maka hasilnya adalah selisih positif sebesar 1,355263. Sehingga menghasilkan Matrix dibawah ini

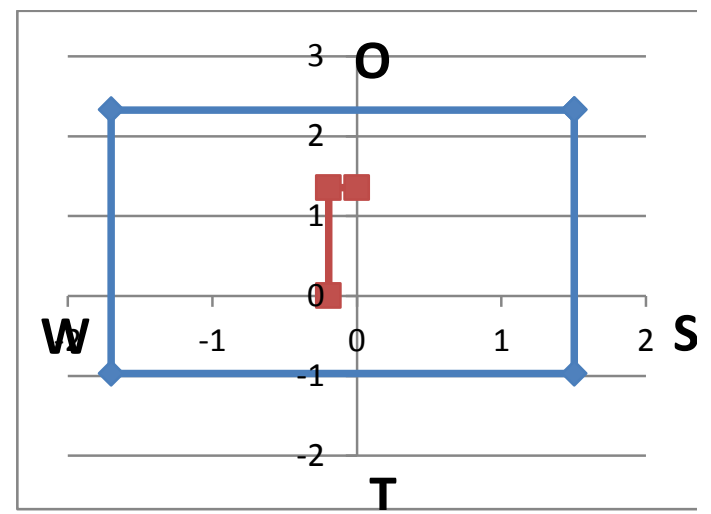

\section{Gambar 7 \\ Matrix SWOT}

Setelah dilakukan perhitungan, maka didapatkan hasil yaitu posisi Perputakaan berada di kuadran III (negatif, positif). Posisi ini menandakan sebuah organisasi yang lemah namun sangat berpeluang. Rekomendasi strategi yang diberikan adalah ubah strategi, artinya organisasi disarankan untuk mengubah strategi sebelumnya. Sebab, strategi yang lama dikhawatirkan sulit untuk dapat menangkap peluang yang ada sekaligus memperbaiki kinerja organisasi. Saran dan strategi yang harus dilakukan diantaranya:
1. Menyediakan tenaga ahli dibidangnya terutama di bidang perpustakaan yang masih terbatas

2. Memperbaiki dan mengembangkan SI Perpustakaan sebelumnya menjadi SI perpustakaan yang terintegrasi.

3. Melengkapi Koleksi Buku di setiap sekolah masing-masing sehingga siswa tidak kesulitan dalam pencarian buku karena keterbatasan fasilitas disekolah

4. Mengembangkan E-Journal dan E-book

5. Kebijakan pemerintah tentang standarisasi nasional mengenai perpustakaan sekolah lebih ditingkatkan

\section{Perencanaan Arsitektur Data, Aplikasi dan teknologi}

Untuk menggambarkan kebutuhan fungsional, peneliti menggunakan Use Case Diagram, berikut ini menggambarkan Sistem Informasi terintegrasi perpustakaan sekolah dengan lingkup penelitian (SMUN 1,SMU Siliwangi, SMK MJPS2, SMK Bina Lestari PUI) di Tasikmalaya.

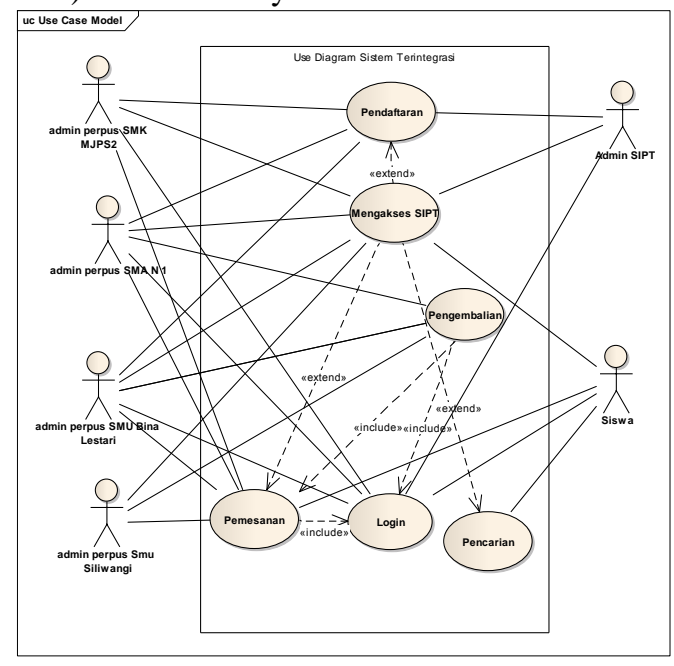

\section{Gambar 8 \\ Use Case SIPT}

Untuk mengambarkan workflow proses bisnis dan urutan aktivitas dalam tubuh sebuah proses digambarkan dengan Activity diagram, diagram ini sangat mirip dengan flowchart karena memodelkan workflow dari satu aktivitas ke aktivitas lain, atau dari aktivitas ke status. Activity diagram bermanfaat untuk menggambarkan parallel behaviour atau menggambarkan beberapa Use Case, Activity Diagram dibuat berdasarkan Use Case diatas 


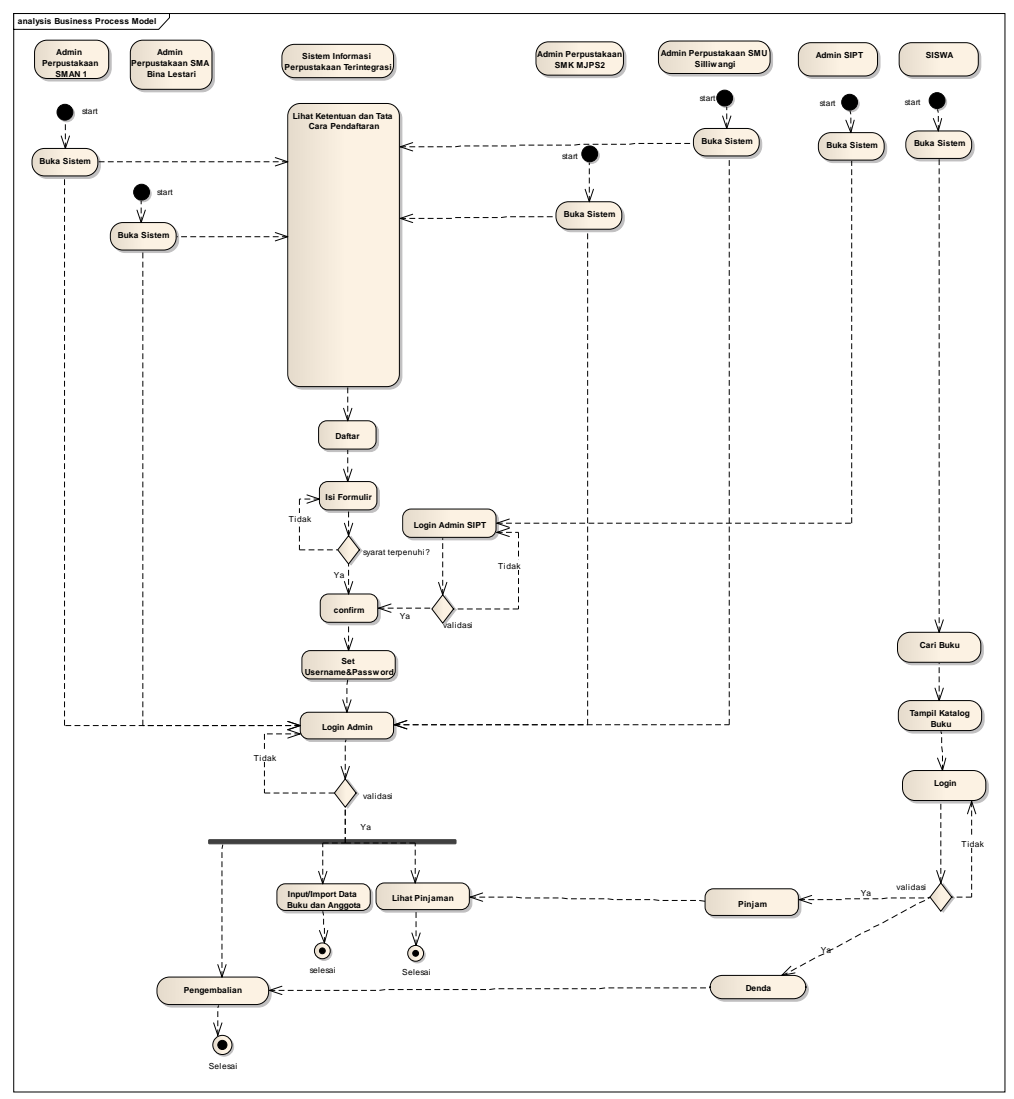

\section{Gambar 9 \\ Activity Diagram SIPT}

Arsitektur teknologi adalah definisi yang dibutuhkan untuk perencanaan agar kebutuhan data dan sistem informasi dapat direalisasikan dan ditingkatkan infrastrukturnya. Arsitektur teknologi yang diusulkan intinya terdapat pada ketersediaan jaringan internet seperti pada gambar berikut ini:

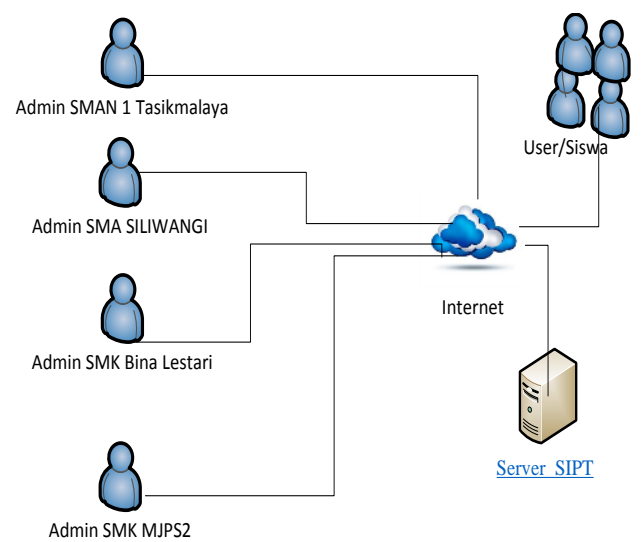

Gambar 10

\section{Rencana Implementasi}

Tabel 3

Jadwal Implementasi

\begin{tabular}{|c|c|c|c|c|c|c|c|c|c|c|c|c|}
\hline \multirow{2}{*}{$\begin{array}{c}\text { NAMA } \\
\text { APLIKASI }\end{array}$} & \multicolumn{12}{|c|}{ BULAN } \\
\hline & 1 & 2 & 3 & 4 & 5 & 6 & 7 & 8 & 9 & 10 & 11 & 12 \\
\hline $\begin{array}{c}\text { Aplikasi } \\
\text { pendaftaran } \\
\text { perpustakaan } \\
\text { baru } \\
\end{array}$ & & & & & & & & & & & & \\
\hline $\begin{array}{c}\text { Aplikasi } \\
\text { registrasi } \\
\text { perpustakaan } \\
\text { baru }\end{array}$ & & & & & & & & & & & & \\
\hline $\begin{array}{c}\text { Aplikasi Data } \\
\text { Anggota }\end{array}$ & & & & & & & & & & & & \\
\hline $\begin{array}{c}\text { Aplikasi Data } \\
\text { Buku }\end{array}$ & & & & & & & & & & & & \\
\hline $\begin{array}{c}\text { Aplikasi } \\
\text { pencarian } \\
\text { buku } \\
\text { berdasarkan } \\
\text { kategori }\end{array}$ & & & & & & & & & & & & \\
\hline $\begin{array}{c}\text { Aplikasi } \\
\text { pencarian } \\
\text { berdasarkan } \\
\text { keywords }\end{array}$ & & & & & & & & & & & & \\
\hline $\begin{array}{c}\text { Aplikasi } \\
\text { Peminjaman } \\
\text { Buku }\end{array}$ & & & & & & & & & & & & \\
\hline $\begin{array}{c}\text { Aplikasi } \\
\text { Pengembalian } \\
\text { Buku }\end{array}$ & & & & & & & & & & & & \\
\hline
\end{tabular}

Arsitektur Teknologi SIPT 


\section{PENUTUP}

\section{Kesimpulan}

Berdasarkan tahapan yang telah dilakukan pada bab sebelumnya, maka dapat iambil kesimpulan Blueprint (data, aplikasi, dan teknologi) yang merupakan landasan pengembangan dan pembangunan sistem informasi terintegrasi untuk perpustakaan di Tasikmalaya yang dirancang menggunakan metode EAP.Hasil penelitian ini menunjukan suatu model standar untuk sistem informasi perpustakaan di Tasikmalaya dalam satu sistem informasi SIPT, yang dirancang dengan menggunakan satu platform berbasis web sehingga memudahkan untuk integrasi.

\section{REFERENSI}

Abdullah, Abrizah. \& Zainab, A.N.. (2007). The digital library as an enterprise: the Zachman approach, Vol 26 No 4, pp. 446-467.

Darmono. (2007). Pengembangan Perpustakaan Sekolah Sebgai Sumber Belajar. Jurnal Perpustakaan Sekolah, Tahun 1 Nomor 1 April 2007, pp. 1-10.

Fatolahi, ali. \& Shamsan, Fereidoon. (2006). investigation into applying UML to the Zachman framework. Vol 8, Issue 2, pp. 133-143.

Fri, Daniel A. (2007). Enterprice Architecture. Air Force Journal of Logistics. 31, 2, pp. 40-46.

Ishak. (2008). Pengelolaan Perpustakaan Berbasis Teknologi Informasi. Jurnal Studi Perpustakaan dan Informasi, Vol.4 No.2, pp. 1-9.

Khairina, Dyna Marisa. (2012). Enterprise Architecture Planing untuk pengembangan sistem informasi perguruan tinggi, Diambil dari: eprints.undip.ac.id/35997/1/Dyna_Marisa _Khairina.pdf. (6 Agustus 2014)

Minoli, Daniel. (2008). Enterprise Architecture A to Z. Frameworks Business Process Modeling SOA and Infrastructure Technology, United States of America:CRC Press

Rajabi, Zeinab. et al. (2013). Enterprise Architecture Development Based on Enterprise Ontology. Journal of
Theoretical and Applied Electronic Commerce Research. VOL 8 ISSUE 2, pp. 85-95.

Surendro, Kridanto. (2007). Pemanfaatan Enterprise Architecture Planning untuk perencanaan strategis sistem informasi.

JURNAL

INFORMATIKA, VOL.8 NO.1, pp. $1-9$.

Undang-Undang RI No 43 Tahun 2007 Pasal Ayat 1 Tentang Perpustakaan

\section{Tentang Penulis}

Agung Baitul Hikmah, Lahir di Tasikmalaya, 19 Agustus 1983 menyelesaikan S1 Jurusan Sistem Informasi STMIK NUSA MANDIRI JAKARTA 2012, S2 Jurusan Ilmu Komputer STMIK NUSA MANDIRI JAKARTA 2013 